(C) The Author(s), 2021. Published by Cambridge University Press for the Arizona Board of Regents on behalf of the University of Arizona. This is an Open Access article, distributed under the terms of the Creative Commons Attribution licence (http://creativecommons.org/licenses/by/4.0/), which permits unrestricted re-use, distribution, and reproduction in any medium, provided the original work is properly cited.

\title{
GENERATION OF TWO NEW RADIOCARBON STANDARDS FOR COMPOUND-SPECIFIC RADIOCARBON ANALYSES OF FATTY ACIDS FROM BOG BUTTER FINDS
}

\author{
Emmanuelle Casanova $^{1}$ (i) $\cdot$ Timothy D J Knowles $^{1,2}$ (D) Isabella Mulhall ${ }^{3}$ \\ Maeve Sikora ${ }^{3} \cdot$ Jessica Smyth $^{4} \cdot$ Richard P Evershed $^{1,2 *}$ (1) \\ ${ }^{1}$ Organic Geochemistry Unit, School of Chemistry, University of Bristol, Cantock's Close, BS8 1TS, Bristol, UK \\ ${ }^{2}$ Bristol Radiocarbon Accelerator Mass Spectrometry Facility, University of Bristol, 43 Woodland Road, Bristol, UK \\ ${ }^{3}$ National Museum of Ireland, Kildare Street, Dublin 2, Ireland \\ ${ }^{4}$ School of Archaeology, University College Dublin, Newman Building, Belfield, Dublin 4, Ireland
}

\begin{abstract}
The analysis of processing standards alongside samples for quality assurance in radiocarbon $\left({ }^{14} \mathrm{C}\right)$ analyses is critical. Ideally, these standards should be similar both in nature and age to unknown samples. A new compound-specific approach was developed at the University of Bristol for dating pottery vessels using palmitic and stearic fatty acids extracted from within the clay matrix and isolated by preparative capillary gas chromatography. Obtaining suitable potsherds for use as processing standards in such analyses is not feasible, so we suggest that bog butter represents an ideal material for such purposes. We sampled ca. $450 \mathrm{~g}$ from two bog butter specimens and homogenized them by melting. We verified the homogeneity of both specimens by characterization of their lipid composition, $\delta^{13} \mathrm{C}$ values of individual lipids, and both bulk- and compound-specific radiocarbon analyses on 10 sub-samples of each bog butter specimen. The weighted means of all ${ }^{14} \mathrm{C}$ measurements on the bog butter standards are $3777 \pm 4$ BP (IB33) and $338 \pm 3$ BP (IB38), thereby providing agerelevant standards for archaeological and historical fatty acids and ensuring the accuracy of radiocarbon determinations of lipids using a compound-specific approach. These new secondary standards will be subjected to an intercomparison exercise to provide robust consensus values.
\end{abstract}

KEYWORDS: bog butter, compound-specific radiocarbon analysis, lipids, radiocarbon standard.

\section{INTRODUCTION}

Identifying and obtaining suitable natural materials for use as radiocarbon $\left({ }^{14} \mathrm{C}\right)$ standards to provide quality assurance for radiocarbon measurements is of primary importance (Bryant et al. 2000; Scott et al. 2004). Radiocarbon standards should be analyzed alongside every batch of samples and should follow the same pretreatment procedures to assess any contamination arising from the laboratory protocol. Creating radiocarbon standards involves finding materials of a similar nature to the samples, which are homogeneous and available in sufficient quantities to enable their long-term use by the radiocarbon community (Bryant et al. 2000; Boaretto et al. 2002; Scott et al. 2004). Robust consensus values of new radiocarbon standards are evaluated by their radiocarbon dating in inter-comparison exercises (Rozanski et al. 1992; Bryant et al. 2000; Scott et al. 2004). Inter-laboratory comparisons on standard materials are also important to aid radiocarbon laboratories in detecting possible biases (offsets) in their ${ }^{14} \mathrm{C}$ measurements (Rozanski et al. 1992; Bryant et al. 2000; Scott et al. 2004).

At the University of Bristol, we recently developed a new method for radiocarbon dating potsherds from their absorbed lipid residues (Casanova et al. 2017, 2018, 2020a). This method uses a compound-specific radiocarbon analysis (CSRA) approach based on commonly recovered food residues: $\mathrm{C}_{16: 0}$ and $\mathrm{C}_{18: 0}$ fatty acids (FAs), characteristic of degraded animal fats (Casanova et al. 2018). The pretreatment procedure initially involves the simultaneous extraction of FAs (and other lipids) from the clay matrix and their methylation into fatty acid methyl esters (FAMEs) using a methanolic/sulphuric acid

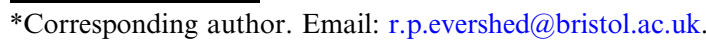


solution. This is followed by the isolation of individual FAME compounds using preparative capillary gas chromatography (pcGC). These isolated FAMEs are then graphitised and ${ }^{14} \mathrm{C}$ dates determined by accelerator mass spectrometry (AMS). These dates are subsequently corrected for the presence of the methyl $\mathrm{C}$ introduced during methylation using a mass balance approach (Casanova et al. 2018, 2020a). To our knowledge, all commercially available fatty acid standards contain "modern" levels of ${ }^{14} \mathrm{C}$, and certainly none of the extensive collection we have measured has shown otherwise. Therefore, in the absence of commercially available FAME standards of background and intermediate ages, our work developing and refining our compound-specific lipid dating technique was performed using a solution of modern $\mathrm{C}_{16: 0}$ and $\mathrm{C}_{18: 0}$ FAMEs and was further validated using archaeological animal fats from archaeological bog butter finds spanning ca. 3000 years (Casanova et al. 2017, 2018). Our first radiocarbon dates of pottery vessels from well-dated sites/cultural phases proved to be entirely compatible with site chronologies and radiocarbon dates on conventional materials (Casanova et al. 2020a). We then applied the new CSRA method to the dating of sites lacking conventionally dateable materials (Casanova et al. 2020a; Stojanovski et al. 2020a), to verify the antiquity of lipids within pots (Dunne et al. 2019; Fewlass et al. 2020), to directly date the use of specific food products (ruminant dairy and adipose fats) (Casanova et al. 2020a, 2020b; Stojanovski et al. 2020b) and to evaluate marine reservoir effects arising from marine product processing in pottery vessels (Casanova et al. 2020c).

No archaeological pottery vessel would, however, be suitable for use as a radiocarbon standard due to the amount of material needed for this purpose as the analyses are destructive in nature. In addition, the vessel would need to be extremely rich in lipids, with a homogeneous concentration and partitioning of lipid in the clay matrix. These, however, are known to be highly heterogenous and variable, depending on the function of the vessel and levels to which it was filled (Charters et al. 1993). Up to now, we have been using pseudo-processing standards obtained by performing an injection of solvent solely ( $n$-hexane) rather than FAME solutions, with trapping sequences mimicking the isolation of the two FAMEs in order to isolate all exogenous $\mathrm{C}$ that would be co-isolated with trapped compounds. The glass wool containing this exogenous $\mathrm{C}$ is transferred along with either IAEA-C7 (approaching the age of archaeological pottery vessels) or a radiocarbon "dead" blank (phthalic anhydride) into an Al capsule before combustion and graphitization (Casanova et al. 2017, 2018). Additionally, a procedural blank is performed alongside every batch of pot lipid extraction and analyzed by GC to ensure no FA contamination occurred in pot lipid extracts before the pcGC step. The pcGC isolation ensures that any contamination (with the exception of FA contamination) from pretreatment processes is completely removed. Therefore, the potential for the introduction of exogenous $\mathrm{C}$ only begins with the isolation of individual FAs in the pcGC. It is of no consequence, therefore, whether or not a processing standard for assessing the accuracy of radiocarbon dates on pot lipids consists of FAs contained within a potsherd.

The archaeological fats known as bog butter that we previously used for the method validation (Casanova et al. 2018) are commonly recovered from peat bogs in Ireland and Scotland (Earwood 1997; Synnott and Downey 2004; Synnott 2010, 2014). Their characteristic lipid profile is that of degraded animal fats with high abundances of free $C_{14: 0}, C_{16: 0}$ and $C_{18: 0}$ FAs and low abundances of hydroxy fatty acids (Evershed et al. 2002; Berstan et al. 2004; Cronin et al. 2007; Smyth et al. 2019). While the origin of most of the Irish specimens analyzed was securely identified as ruminant dairy fats (Smyth et al. 2019), probably originating from cattle milk (Mattiangeli et al. 2020), Scottish examples have both a 
ruminant dairy and ruminant adipose origin (Berstan et al. 2004). Approximately 500 finds of bog butter are on record as having been recovered from peat bogs in Ireland. With around 50 radiocarbon dates previously determined for these, they range in date from the Bronze Age to the post-Medieval era (Downey et al. 2006; Synnott and Sikora 2018; Smyth et al. 2019). Some bog butter specimens were dated using both bulk and compound-specific determinations and statistically indistinguishable results were obtained using both approaches (Casanova et al. 2018). These archaeological and historical bog butter finds therefore represent ideal materials from which to generate new radiocarbon standards due to their nature, age and size. These materials would be particularly suited for CSRA of FAs, extracted from archaeological, historical or environmental matrices.

We present herein (i) the selection process used to identify two bog butter finds to be prepared as radiocarbon processing standards, (ii) their cleaning, (iii) their homogenization, and finally, (iv) their homogeneity assessment by lipid composition, stable carbon isotope and radiocarbon analyses.

\section{MATERIALS AND METHODS}

\section{Sampling}

Following a rigorous selection process by the National Museum of Ireland (NMI), nine samples of bog butter were selected to assess their suitability for use as standards. In order to determine this, samples ranging in size from 20 to $50 \mathrm{mg}$ were taken from beneath the surface of the bog butter mass. This was carried out under sterile conditions using a clean scalpel and the samples were subsequently stored in glass vials. Sampling and handling of the bog butter samples was performed using nitrile gloves to prevent contamination with skin lipids. Solvent washed scalpels and tweezers were used at all times. All sampling and handling of the bog butter finds was carried out under the supervision of and with licence from the National Museum of Ireland (Licences to Alter and Export Nos 6630; 6717; Licence to Alter No 6669). Following the selection of the two bog butter specimens to be used as the standards (see results section), between $400-500 \mathrm{~g}$ of each was sampled using solvent washed scalpels and tweezers. These were stored in covered aluminium trays with fitted lids then put in sealed plastic bags to prevent any contamination during sampling and transfer to Bristol.

\section{Cleaning and Homogenization of the Bog Butter Standards}

All steps were performed using gloves, in a fume hood and all surfaces covered with clean aluminium foil. Cleaning and homogenization methods were tested on 1-2 g of the bog butter specimens before being performed on the remaining bulk samples. The bog butter specimens were freeze-dried for $72 \mathrm{hr}$ to remove residual water and were then separated into sub-samples of approximately $40 \mathrm{~g}$, which were transferred to large culture tubes (i.d. $5 \mathrm{~cm}$ ). These sub-samples were then melted at $70-75^{\circ} \mathrm{C}$ on a heating block and then centrifuged (3000 rpm, $5 \mathrm{~min}$ ) while molten to achieve separation of fats from visible contaminants (denser than the fats). The melting and centrifuging process was repeated until all the fat (pale yellow colored oil melt) separated from the contaminants (black colored particulates). Once cooled, the fats and contaminants were removed from the tubes using a spatula and physically separated using a scalpel. The contaminants with adhering fat were re-melted and re-centrifuged until no more separation of particulates from the fats was achievable. The various particle-free bog butter samples were then combined and melted in a large 
beaker on a hot plate at $70-75^{\circ} \mathrm{C}$ and stirred with a glass agitator to ensure homogeneity. The liquid fats from the two bog butter specimens were poured into separate trays covered with aluminium foil (to $<0.5 \mathrm{~cm}$ thickness) and allowed to cool. Once solidified, the bog butter samples were sliced into 8 pieces of around $5 \times 8 \mathrm{~cm}$ for storage. Any loose material which remained in the beaker and tray was collected and transferred to glass vials for storage.

\section{Lipid Biomarker Analyses}

Lipid extraction and methylation were performed on $\sim 2 \mathrm{mg}$ of the bog butter samples, following established procedures (Correa-Ascencio and Evershed 2014). Bog butter samples were treated with $\mathrm{H}_{2} \mathrm{SO}_{4} / \mathrm{MeOH}\left(4 \%, v / v, 5 \mathrm{~mL}, 70^{\circ} \mathrm{C}, 1 \mathrm{hr}\right)$. Ultrapure (MilliQ $\left.{ }^{\mathrm{TM}}\right)$ water $(2 \mathrm{~mL})$ was added and lipids were extracted using $n$-hexane $(4 \times 3 \mathrm{~mL})$. After mixing, the $n$-hexane fractions were transferred to a $3.5 \mathrm{~mL}$ vial and blown down under a gentle stream of $\mathrm{N}_{2}$. An aliquot (1/4) of the total lipid extract (TLE) was blown down and diluted using an appropriate amount of $n$-hexane before analyses by gas chromatography (GC), GC-mass spectrometry (GC-MS) and GC-combustion-Isotope ratio mass spectrometry (GC-C-IRMS).

GC analyses were performed on an Agilent Technologies 7890A instrument fitted with a flame ionization detector. TLEs $(1 \mu \mathrm{L})$ were injected into a non-polar column (DB 1 stationary phase, $15 \mathrm{~m} \times 0.32 \mathrm{~mm}$ i.d., $0.1 \mu \mathrm{m}$ thickness, Agilent Technologies) at a constant flow (He, $10 \mathrm{~mL} \cdot \mathrm{min}^{-1}$ ). The temperature program started at $50^{\circ} \mathrm{C}$ for $2 \mathrm{~min}$ then increased to $350^{\circ} \mathrm{C}$ at a rate of $10^{\circ} \mathrm{C} \cdot \mathrm{min}^{-1}$ and held for $10 \mathrm{~min}$. GC-MS analyses were performed on a Finnigan Trace GC coupled with a Finnigan Trace MS quadrupole. TLEs $(1 \mu \mathrm{L})$ were injected into a non-polar column (DB 1 stationary phase, $50 \mathrm{~m} \times 0.32 \mathrm{~mm}$ i.d., $0.17 \mu \mathrm{m}$ thickness, Agilent Technologies). The temperature program was identical to GC analyses, but with a maximum temperature of $300^{\circ} \mathrm{C}$. The MS used an electron ionization (EI) mode operating at $70 \mathrm{eV}$. The total ion current (TIC) was acquired over the range $\mathrm{m} / \mathrm{z}$ 50-650 Da. GC-C-IRMS analyses were performed on an Agilent technologies 7890A coupled with an IsoPrime GC5 combustion interface and an IsoPrime 100 MS. TLEs were injected in a similar column and using a similar temperature program as for GC-MS, but with a starting temperature of $40^{\circ} \mathrm{C}$. The MS used an EI mode operating at $70 \mathrm{eV}$ and had three Faraday cups collecting masses $\mathrm{m} / \mathrm{z} 44,45$, and 46 .

\section{Radiocarbon Analyses}

Bulk radiocarbon dating of the bog butter specimens (1 $\mathrm{mg}$ of $\mathrm{C}$ ) was performed by direct combustion and graphitization of $\sim 1.2 \mathrm{mg}$ of butter in a Vario cube Elemental Analyser (EA) linked to an Ion Plus Automated Graphitisation Equipment 3 (AGE3). For CSRA analyses (200-300 $\mu \mathrm{g}$ of $\mathrm{C}$ per isolated compound), $\sim 3 \mathrm{mg}$ of lipids were methylated as described above, then isolated following the pcGC procedure described in Casanova et al. (2018). Briefly, the $\mathrm{C}_{16: 0}$ and $\mathrm{C}_{18: 0}$ solutions (the FA with lowest abundance was at a concentration of $\left.\sim 5 \mu \mathrm{g} \mathrm{C} \mu \mathrm{L}^{-1}\right)$ were injected $(1 \mu \mathrm{L} \times 40$ injections) into a DB1 column (Rxi-1ms, $30 \mathrm{~m} \times 0.53 \mathrm{~mm}$ i.d., $1.5 \mu \mathrm{m}$ thickness, Restek) in a Hewlett-Packard series II GC coupled via a transfer line (heated at $310^{\circ} \mathrm{C}$ ) to a Gerstel preparative fraction collector (heated at $310^{\circ} \mathrm{C}$ ). The $\mathrm{C}_{16: 0}$ and $\mathrm{C}_{18: 0}$ FAMEs were isolated into individual solventless traps based on their retention time. The glass wool containing the isolated FAMEs was transferred directly into an $\mathrm{Al}$ capsule for combustion and $\mathrm{CO}_{2}$ reduction into graphite on activated iron catalyst $\left(2 \mathrm{hr}, 580^{\circ} \mathrm{C}\right)$ using an EA-AGE3 system. Size-matched standards and blanks were analyzed alongside every batch. The AMS measurements were performed 
on the Bris-MICADAS accelerator at the Bristol Radiocarbon Accelerator Mass Spectrometry Facility. Radiocarbon dates determined for FAMEs were corrected for the derivative C using a mass balance and combined as described previously (Casanova et al. 2018, 2020a). The statistical consistency of radiocarbon measurements was evaluated at the $5 \%$ level using a $\chi^{2}$ test (Ward and Wilson 1978), and the values combined as the weighted mean as described in Casanova et al. (2020a).

\section{RESULTS}

\section{Preselection of the Bog Butter Standards}

The criteria used for identifying suitable bog butter finds for use as radiocarbon standards were (1) bog butter specimens large enough to allow up to $500 \mathrm{~g}$ to be sampled with minimal impact on their historical or cultural value and their overall integrity; (2) specimens that survived in several pieces (either post-excavation, at the time of discovery, or at the time of reporting) and not deemed suitable for museum display; (3) absence of conservation treatments involving organic-based products; (4) absence of modern contamination deriving from the excavation and storage (e.g. plasticizers from plastic bags); (5) lipid distribution with approximately equal abundances of $\mathrm{C}_{16: 0}$ and $\mathrm{C}_{18: 0} \mathrm{FAs}$ (i.e. ratio $\mathrm{C}_{16: 0} / \mathrm{C}_{18: 0}$ as close as possible to 1) to enable the same masses of each fatty acid to be extracted and isolated during CSRA; (6) lipid distribution with relatively low abundances of $\mathrm{C}_{18: 1}$ FA or other compounds which could partially coelute with the $\mathrm{C}_{18: 0}$ (or $\mathrm{C}_{16: 0}$ ) FA; and (7) in cases where several specimens fulfil the above criteria, samples with significantly different dates were considered desirable.

Bog butter specimens contained in vessels were oftentimes subject to wax treatment in the past for the purposes of consolidation of the vessel. This process rendered these particular specimens unsuitable for our current purpose (criterion 3). From the remaining specimens, we identified nine of large size (>10 kg; criterion 1) and in several pieces (criterion 2) as being the potential candidates for use as standards (Table 1). Three of them (IB4, IB20, IB29) had been previously analyzed and were not re-sampled (Smyth et al. 2019). At this stage, two different areas of each of the remaining bog butter specimens were sub-sampled for both lipid and radiocarbon analyses.

The lipid analyses by GC and GC-MS revealed all nine sampled specimens to be free of obvious contamination from storage or restoration work (criteria 3, 4). The $\mathrm{C}_{14: 0}, \mathrm{C}_{16: 0}$ and $\mathrm{C}_{18: 0} \mathrm{FAs}$ were found to be dominant in the TLE of all the specimens. Some of the bog butter specimens also contained hydroxy fatty acids (OHFAs; the 10- $\mathrm{C}_{18: 0}$ OHFA being dominant), biomarkers of adipocere formation (Smyth et al. 2019), in appreciable abundances. Only five specimens (IB4, IB29, IB33, IB37, IB38) showed a peak area ratio of $\mathrm{C}_{16: 0} / \mathrm{C}_{18: 0} \mathrm{FAs}$ below 2 (Table 1; criterion 5). Sample IB37, however, displayed significantly different $C_{16: 0} / C_{18: 0}$ FA peak area ratios between the two sub-samples with one at 1.6 and the other at 2.7, suggesting its lipid composition was inhomogeneous. Two specimens (IB29, IB34) showed the presence of $\mathrm{C}_{18: 1} \mathrm{FA}$ at similar abundance to the $\mathrm{C}_{18: 0} \mathrm{FA}$, and thus were not suitable (criterion 6). The $\delta^{13} \mathrm{C}$ values on the $\mathrm{C}_{16: 0}$ and $\mathrm{C}_{18: 0}$ FAs measured by GC-C-IRMS of six specimens (IB4, IB20, IB29, IB34, IB36, IB38) plotted firmly in the reference range of ruminant dairy animals (Copley et al. 2003) and two others (IB33, IB35) at the edge of this reference range confirming that all of these specimens were dairy fats (Table 1, Figure 1a). Sample IB37, however, displayed $\delta^{13} \mathrm{C}_{16: 0 / 18: 0}$ values outside the reference range of 
Table 1 Bog butter specimens preselected, bulk conventional ${ }^{14} \mathrm{C}$ age, $\mathrm{C}_{16: 0} / \mathrm{C}_{18: 0}$ peak area ratio and stable carbon isotope values.

\begin{tabular}{|c|c|c|c|c|c|c|c|c|}
\hline Museum \# & Location & $\begin{array}{l}\text { Bog } \\
\text { butter \# }\end{array}$ & BRAMS\# & $\begin{array}{l}\text { Conventional } \\
{ }^{14} \mathrm{C} \text { age }\end{array}$ & $\begin{array}{c}\text { Ratio } \\
\mathrm{C}_{16: 0} / \mathrm{C}_{18: 0}\end{array}$ & $\delta^{13} C_{16: 0}(\%)$ & $\delta^{13} C_{18: 0}(\% 0)$ & $\Delta^{13} \mathrm{C}(\% 0)$ \\
\hline $1986: 125$ & Ballindown, Co. Offaly & IB4 & BRAMS-1090 & $1924 \pm 26$ & 1.85 & -29.3 & -34.1 & -4.9 \\
\hline 1987:112 & Ards Beg, Co. Donegal & IB20 & BRAMS-1104 & $1198 \pm 25$ & 2.43 & -27.8 & -33.4 & -5.6 \\
\hline 2018:27 & Gowlaun, Co. Mayo & IB29 & BRAMS-1111 & $357 \pm 25$ & 1.18 & -28.8 & -34.3 & -5.6 \\
\hline \multirow[t]{2}{*}{ 2016:177 } & Ballykean, Co. Offaly & IB33-1 & BRAMS-2752 & $3765 \pm 26$ & 1.54 & -31.3 & -35.8 & -4.4 \\
\hline & & IB33-2 & BRAMS-2753 & $3757 \pm 26$ & 1.55 & -31.1 & -35.8 & -4.7 \\
\hline \multirow[t]{2}{*}{ 2016:182 } & Pallasboy, Co. Westmeath & IB34-1 & BRAMS-2754 & $1913 \pm 25$ & 2.04 & -29.7 & -34.9 & -5.2 \\
\hline & & IB34-2 & BRAMS-2755 & $1921 \pm 25$ & 2.29 & -30.1 & -34.8 & -4.7 \\
\hline \multirow[t]{2}{*}{ 2018:21 } & Shancloon, Co. Galway & IB35-1 & BRAMS-2756 & $1972 \pm 25$ & 2.34 & -31.1 & -34.6 & -3.6 \\
\hline & & IB35-2 & BRAMS-2757 & $1972 \pm 25$ & 2.38 & -30.8 & -34.6 & -3.8 \\
\hline \multirow[t]{2}{*}{ 1996:39.1 } & Holywell Lower, Co. Mayo & IB36-1 & BRAMS-2758 & $2044 \pm 25$ & 2.21 & -30.6 & -34.6 & -4.0 \\
\hline & & IB36-2 & BRAMS-2759 & $2040 \pm 25$ & 2.21 & -30.6 & -34.8 & -4.2 \\
\hline \multirow[t]{2}{*}{$1975: 235$} & Annaghbeg, Co. Kerry & IB37-1 & BRAMS-2760 & $2114 \pm 25$ & 1.54 & -32.5 & -35.7 & -3.2 \\
\hline & & IB37-2 & BRAMS-2761 & $2123 \pm 25$ & 2.67 & -32.3 & -34.8 & -2.5 \\
\hline \multirow[t]{2}{*}{$2007: 48$} & Near Athlone, Co. Westmeath & IB38-1 & BRAMS-2762 & $330 \pm 25$ & 1.35 & -29.2 & -34.0 & -4.8 \\
\hline & & IB38-2 & BRAMS-2763 & $330 \pm 25$ & 1.15 & -29.7 & -33.9 & -4.1 \\
\hline
\end{tabular}


(a)



(b)

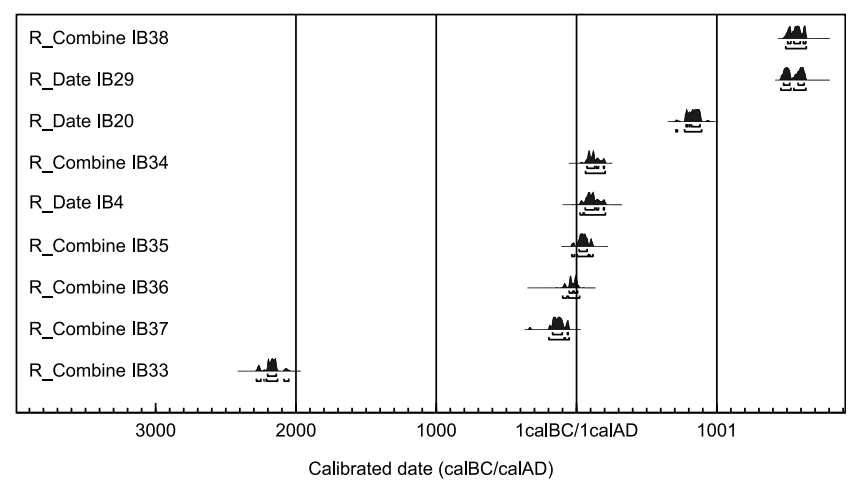

Figure 1 (a) $\delta^{13} \mathrm{C}_{18: 0}$ values plotted against $\delta^{13} \mathrm{C}_{16: 0}$ values and (b) calibrated bulk radiocarbon dates (calibrated using OxCal v4.4.2 and the IntCal20 terrestrial calibration curve; Reimer et al. 2020) for the nine preselected bog butter specimens.

ruminant animals with one sub-sample plotting in the dairy region $\left(\Delta^{13} \mathrm{C}<-3.1 \%\right)$ and the other in the ruminant adipose region $\left(\Delta^{13} \mathrm{C}>-3.1 \%\right.$ ), thus being of uncertain origin.

The bulk radiocarbon dates on the sub-samples for bog butter specimens IB33 to IB38 inclusive provided statistically consistent measurements. The radiocarbon dates identified one specimen (IB33) as dating to the Early Bronze Age, five (IB4, IB34 to IB37 inclusive) dating to the Iron Age, one (IB20) of medieval date and two (IB29, IB38) of post-medieval date (Table 1, Figure 1b).

Only three specimens, therefore, matched all the selection criteria. Specimen IB4 has a $\mathrm{C}_{16: 0} / \mathrm{C}_{18: 0}$ ratio of 1.85 and dates to $1924 \pm 26 \mathrm{BP}$, IB33 has an average ratio of 1.55 and dates to $3765 \pm 26 \mathrm{BP}$, finally, IB38 has an average ratio of 1.25 and dates to $330 \pm 18 \mathrm{BP}$. Specimens IB33 and IB38 were selected as those bog butter specimens to be used as radiocarbon standards as they exhibited the smallest $\mathrm{C}_{16: 0} / \mathrm{C}_{18: 0}$ ratios (criterion 5 ). These specimens also display very distinct radiocarbon ages providing one standard in the range of prehistoric pottery vessels and another in the range of historical vessels (criterion 7).

\section{Cleaning and Homogenization}

We sampled $495.37 \mathrm{~g}$ of IB33 and $426.12 \mathrm{~g}$ of IB38 for the creation of radiocarbon standards (Figure 2 a1-2, b1-2). During the initial freeze-drying step, $17.0 \%$ of the mass of IB33, and 3.3\% of the mass of IB38, were lost as water. After the removal of visible contaminants (animal hair, pieces of ancient wooden container and peat particles, stored afterwards in separate glass vials) using the melting and centrifuging process, $377.6 \mathrm{~g} \mathrm{(76.6 \%} \mathrm{of} \mathrm{the} \mathrm{initial} \mathrm{mass)} \mathrm{of} \mathrm{IB33} \mathrm{and} 406.6$ $\mathrm{g}(95.4 \%$ of the initial mass) of IB38 remained for homogenization (Figure $2 \mathrm{a3}, \mathrm{b} 3)$.

Once homogenized, cooled and solidified (Figure 2 a4, b4), the bog butter specimens were sliced into eight plates with total masses of $372.4 \mathrm{~g}$ (75.0\% of the initial mass) and $400.6 \mathrm{~g}$ (94.0\% of the initial mass) for IB33 and IB38, respectively (Figure 2 a5, b5). The remaining loose material account for $2.5 \mathrm{~g}(0.4 \%$ of the initial mass $)$ and $2.9 \mathrm{~g}(0.7 \%$ of the initial mass) of IB33 and IB38, respectively. In total, $373.9 \mathrm{~g}$ (75.5\% of the initial mass) of IB33 and $403.5 \mathrm{~g}(94.7 \%$ of the initial mass) of IB38 were homogenized and constitute the 
(a)

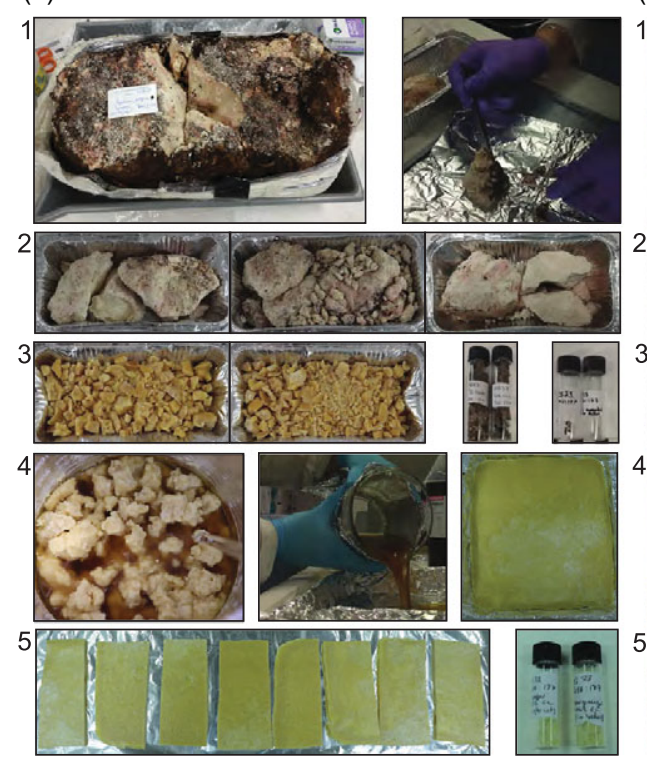

(b)

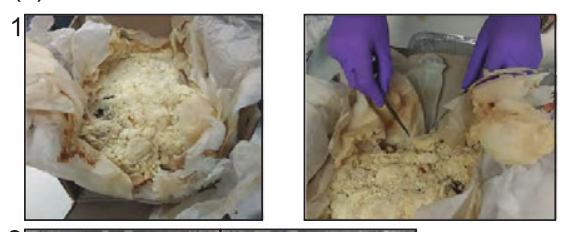

(riag)
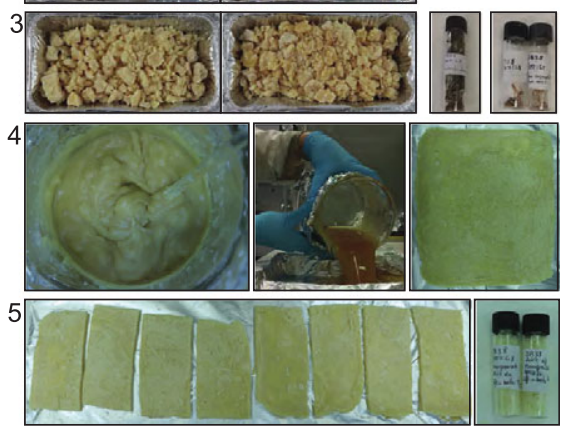

Figure 2 Pictures of the main steps to generate homogenous radiocarbon standards from (a) IB33 and (b) IB38 bog butter finds: 1. Bog butter specimens from the NMI collections (left) and sampling with tweezers and scalpel removing obvious contaminants (e.g. pieces of wooden container) (right). 2. Sampled masses for cleaning. 3. Masses collected after removal of visible contaminants by melting and centrifuging (left), isolated peat-like contaminant materials (middle), isolated wooden materials and animal hair (right). 4. Homogenization by melting in a large beaker (left), pouring in a tray covered in foil (middle) and cooled bog butters as thin tablets (right). 5. Bog butter standards divided into eight pieces (left) and remaining material collected from the beaker and after slicing (right).

amounts of the new radiocarbon standards available. The different plates are now stored individually wrapped in foil in aluminium trays to avoid potential contamination during future handling of the standards.

\section{Homogeneity Assessment}

To assess the homogeneity in terms of lipid composition and radiocarbon age, the eight plates and the two vials of material were analyzed, resulting in a total of 10 analyses per bog butter specimen.

The lipid analyses (Table 2, Figure $3 \mathrm{a}, \mathrm{b}$ ) revealed a $\mathrm{C}_{16: 0} / \mathrm{C}_{18: 0}$ peak area ratio average of $1.62 \pm 0.03$ (SD) with extreme values of 1.59 and 1.67 for IB33 and an average of $1.29 \pm 0.05$ (SD) with extreme values of 1.26 and 1.41 for IB38. These values are close to the original ratios and suggest the lipid profiles were not altered during the preparation procedure and the bog butter standards are homogeneous. The $\delta^{13} \mathrm{C}_{16: 0 / 18: 0}$ values from the different pieces are statistically indistinguishable as the means were found to be $\delta^{13} \mathrm{C}_{16: 0}=-31.5 \pm 0.1 \%$ and $\delta^{13} \mathrm{C}_{18: 0}=-35.6 \pm 0.1 \%$ o $\left(\mathrm{T}^{\prime}=0.4, \mathrm{~T}^{\prime}(5 \%)=16.9, \nu=9\right.$ and $\mathrm{T}^{\prime}=0.5, \mathrm{~T}^{\prime}(5 \%)=16.9, \nu=9$, respectively) for IB33 and $\delta^{13} \mathrm{C}_{16: 0}=-29.3 \pm 0.1 \%$ and $\delta^{13} \mathrm{C}_{18: 0}=-33.6 \pm 0.2 \%$ o $\left(\mathrm{T}^{\prime}=0.3, \mathrm{~T}^{\prime}(5 \%)=16.9, \nu=9\right.$ and $\mathrm{T}^{\prime}=0.9, \mathrm{~T}^{\prime}(5 \%)=16.9$, $\nu=9$, respectively) for IB38 (Figure 2c). These results further support the homogeneity of the two bog butter standards. 
Table 2 Results of homogenization for IB33 and IB38. Mass of pieces, ratio of $\mathrm{C}_{16: 0} / \mathrm{C}_{18: 0}$, stable carbon isotope analyses (analytical error is $0.5 \%$ and averages are reported), bulk and CSRA measurements reported as the conventional radiocarbon age. ${ }^{*}$ Measurement excluded (outliers or $\mathrm{C}_{16: 0}$ and $\mathrm{C}_{18: 0}$ ages non-statistically identical).

\begin{tabular}{|c|c|c|c|c|c|c|c|c|c|c|c|}
\hline Bog Butter\# & Piece & $\begin{array}{l}\text { Mass } \\
(\mathrm{g})\end{array}$ & $\begin{array}{c}\text { Ratio } \\
\mathrm{C}_{16} / \mathrm{C}_{18}\end{array}$ & $\begin{array}{c}\delta^{13} C_{16: 0} \\
(\% 0)\end{array}$ & $\begin{array}{c}\delta^{13} \mathrm{C}_{18: 0} \\
(\% 0)\end{array}$ & $\begin{array}{c}\Delta^{13} \mathrm{C} \\
(\% 0)\end{array}$ & BRAMS\# & $\begin{array}{l}\text { Bulk age } \\
\text { (BP) }\end{array}$ & $\begin{array}{c}\mathrm{C}_{16: 0} \text { age } \\
\text { (BP) }\end{array}$ & $\begin{array}{c}\mathrm{C}_{18: 0} \text { age } \\
\text { (BP) }\end{array}$ & $\begin{array}{c}\text { Combined } \\
\mathrm{C}_{16: 0 /} \mathrm{C}_{18: 0} \\
\text { age (BP) }\end{array}$ \\
\hline IB33 & Plate 1 & 47.71 & 1.61 & -31.5 & -35.6 & -4.2 & BRAMS-3403 & $3788 \pm 14$ & $3803 \pm 31$ & $3742 \pm 29$ & $3769 \pm 25$ \\
\hline \multirow[t]{10}{*}{ 2016:177 } & Plate 2 & 37.29 & 1.67 & -31.7 & -35.7 & -4.0 & BRAMS-3404 & $3782 \pm 14$ & $3779 \pm 26$ & $3730 \pm 27$ & $3756 \pm 24$ \\
\hline & Plate 3 & 40.98 & 1.59 & -31.4 & -35.5 & -4.0 & BRAMS-3405 & $3797 \pm 15$ & $3785 \pm 31$ & $3767 \pm 28$ & $3774 \pm 25$ \\
\hline & Plate 4 & 50.81 & 1.65 & -31.6 & -35.6 & -4.0 & BRAMS-3406 & $3795 \pm 15$ & $3755 \pm 27$ & $3792 \pm 35$ & $3765 \pm 25$ \\
\hline & Plate 5 & 46.44 & 1.58 & -31.4 & -35.5 & -4.1 & BRAMS-3407 & $3780 \pm 14$ & $3779 \pm 30$ & $3791 \pm 27$ & $3786 \pm 25$ \\
\hline & Plate 6 & 49.08 & 1.61 & -31.5 & -35.4 & -3.9 & BRAMS-3408 & $3755 \pm 14$ & $3749 \pm 30$ & $3764 \pm 27$ & $3758 \pm 24$ \\
\hline & Plate 7 & 44.60 & 1.59 & -31.5 & -35.5 & -4.0 & BRAMS-3409 & $3780 \pm 14$ & $3771 \pm 27$ & $3848 \pm 35$ & $3791 \pm 25$ \\
\hline & Plate 8 & 54.55 & 1.66 & -31.6 & -35.5 & -3.9 & BRAMS-3410 & $\begin{array}{l}3685 \pm 14^{*} \\
3765 \pm 17\end{array}$ & $3802 \pm 26$ & $3787 \pm 35$ & $3798 \pm 26$ \\
\hline & Vial 1 & 2.14 & 1.61 & -31.5 & -35.5 & -4.0 & BRAMS-3411 & $3758 \pm 14$ & $3754 \pm 30$ & $3772 \pm 29$ & $3764 \pm 27$ \\
\hline & Vial 2 & 0.38 & 1.62 & -31.7 & -35.7 & -4.0 & BRAMS-3412 & $3767 \pm 15$ & $3804 \pm 28$ & $3787 \pm 28$ & $3796 \pm 24$ \\
\hline & Total & 373.88 & 1.62 & -31.5 & -35.6 & -4.0 & Weighted mean & $3777 \pm 5$ & $3778 \pm 9$ & $3774 \pm 9$ & $3775 \pm 8$ \\
\hline \multirow[t]{12}{*}{ IB38 2007:48 } & Plate 1 & 50.49 & 1.28 & -29.5 & -33.9 & -4.4 & BRAMS-3413 & $349 \pm 13$ & $338 \pm 27$ & $375 \pm 27$ & $357 \pm 24$ \\
\hline & Plate 2 & 46.71 & 1.41 & -29.3 & -33.5 & -4.3 & BRAMS-3414 & $347 \pm 13$ & $319 \pm 26$ & $346 \pm 27$ & $332 \pm 24$ \\
\hline & Plate 3 & 46.60 & 1.24 & -29.5 & -33.5 & -4.1 & BRAMS-3415 & $338 \pm 13$ & $317 \pm 28$ & $344 \pm 28$ & $330 \pm 24$ \\
\hline & Plate 4 & 44.92 & 1.31 & -29.2 & -33.6 & -4.3 & BRAMS-3416 & $348 \pm 13$ & $332 \pm 28$ & $342 \pm 26$ & $338 \pm 24$ \\
\hline & Plate 5 & 56.46 & 1.26 & -29.3 & -33.6 & -4.3 & BRAMS-3417 & $327 \pm 13$ & $329 \pm 28^{*}$ & $409 \pm 26^{*}$ & \\
\hline & & & & & & & & & $348 \pm 40$ & $345 \pm 40$ & $347 \pm 29$ \\
\hline & Plate 6 & 45.79 & 1.31 & -29.3 & -33.4 & -4.1 & BRAMS-3418 & $350 \pm 13$ & $339 \pm 26$ & $321 \pm 31$ & $334 \pm 24$ \\
\hline & Plate 7 & 54.21 & 1.28 & -29.2 & -33.3 & -4.1 & BRAMS-3419 & $328 \pm 13$ & $324 \pm 28$ & $313 \pm 27$ & $318 \pm 24$ \\
\hline & Plate 8 & 55.38 & 1.30 & -29.3 & -33.6 & -4.3 & BRAMS-3420 & $333 \pm 13$ & $340 \pm 28$ & $311 \pm 27$ & $324 \pm 24$ \\
\hline & Vial 1 & 1.79 & 1.25 & -29.3 & -33.6 & -4.3 & BRAMS-3421 & $346 \pm 13$ & $334 \pm 27$ & $335 \pm 27$ & $335 \pm 24$ \\
\hline & Vial 2 & 1.13 & 1.29 & -29.3 & -33.5 & -4.3 & BRAMS-3422 & $327 \pm 13$ & $344 \pm 25$ & $314 \pm 26$ & $330 \pm 23$ \\
\hline & Total & 403.47 & 1.29 & -29.3 & -33.6 & -4.2 & Weighted mean & $339 \pm 4$ & $333 \pm 9$ & $334 \pm 9$ & $334 \pm 8$ \\
\hline
\end{tabular}


(a)

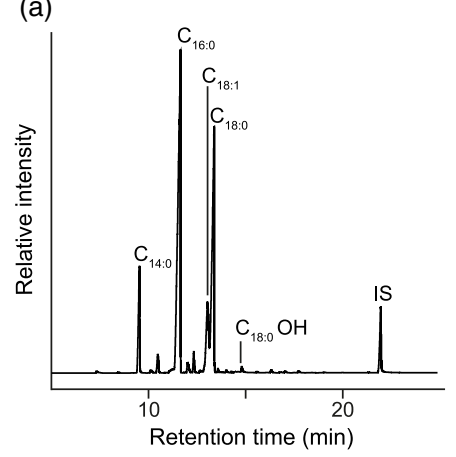

(b)

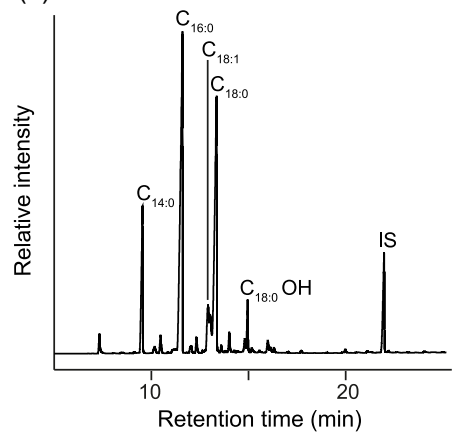

(c)

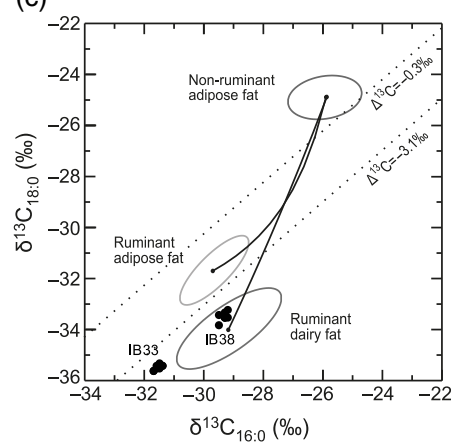

Figure 3 GC lipid profile of (a) IB33 (plate 1) and (b) IB38 (plate 1) after homogenization. (c) $\delta^{13} \mathrm{C}_{18: 0}$ values plotted against $\delta^{13} \mathrm{C}_{16: 0}$ values after homogenization.

Both bulk and CSRA determinations were performed to assess the homogeneity in radiocarbon ages of the subsamples (Table 2). Our quality assurance criteria for the CSRA approach is to obtain statistically consistent ages at the $5 \%$ level between the two fatty acids (Casanova et al. 2018, 2020a).

For bulk measurements on IB33, one measurement (plate 8) was detected as a statistical outlier and was re-measured. With the new date on plate 8 , the bulk dates are statistically identical at the $5 \%$ level $\left(\mathrm{T}^{\prime}=8.7, \mathrm{~T}^{\prime}(5 \%)=16.9, \nu=9\right)$ and give a weighted mean of $3777 \pm 5 \mathrm{BP}$. For CSRA measurements, the $\mathrm{C}_{16: 0}$ and $\mathrm{C}_{18: 0} \mathrm{FA}$ radiocarbon ages pass the statistical consistency test at the $5 \%$ level for all of the 10 plates and vials. The measurements on individual fatty acids are statistically consistent at the $5 \%$ level $\left(\mathrm{T}^{\prime}=14.3, \mathrm{~T}^{\prime}(5 \%)=30.1, \nu=19\right)$ and give a weighted mean of $3776 \pm 6 \mathrm{BP}$. If the $\mathrm{C}_{16: 0}$ and $\mathrm{C}_{18: 0} \mathrm{FA}$ ages are combined for each piece prior to calculating their weighted means (as would usually be the case when reporting an age of a pottery vessel), the results are also statistically consistent $\left(T^{\prime}=3.8, T^{\prime}(5 \%)=16.9, v=9\right)$ and their weighted mean is $3775 \pm 8$ BP. For this bog butter specimen, the CSRA weighted mean age (both using individual and combined $\mathrm{C}_{16: 0}$ and $\mathrm{C}_{18: 0}$ FA measurements) is statistically indistinguishable to that obtained on bulk material $\left(\mathrm{T}^{\prime}=0.0, \mathrm{~T}^{\prime}(5 \%)=3.8, v=1\right.$ for both). Taken all together, individual bulk- and CSRA measurements for the butter IB33-2016:177 are statistically indistinguishable whether using the individual $\left(\mathrm{T}^{\prime}=23, \mathrm{~T}^{\prime}(5 \%)=42.6, v=29\right)$ or combined $\left(\mathrm{T}^{\prime}=12.5, \mathrm{~T}^{\prime}(5 \%)=30.1, \nu=19\right)$ ages of the $\mathrm{C}_{16: 0}$ and $\mathrm{C}_{18: 0}$ FAs. The weighted mean was found to be $3777 \pm 4$ BP in both cases.

The bulk measurements on IB38 are statistically indistinguishable at the $5 \%$ level $\left(\mathrm{T}^{\prime}=5.1\right.$, $\left.\mathrm{T}^{\prime}(5 \%)=16.9, \nu=9\right)$ and give a weighted mean of $339 \pm 4$ BP. For CSRA measurements on IB38, the $\mathrm{C}_{16: 0}$ and $\mathrm{C}_{18: 0} \mathrm{FA}$ radiocarbon ages pass the statistical consistency test at the $5 \%$ level for nine plates and vials. The CSRA of Plate 5 provided inconsistent measurements, the $\mathrm{C}_{18: 0}$ FA radiocarbon age likely being erroneous due to its older age and was re-measured. The second CSRA measurements on this plate are statistically consistent and are used in the remainder of the analyses. The measurements on individual $\mathrm{C}_{16: 0}$ and $\mathrm{C}_{18: 0}$ FAs are statistically consistent at the $5 \%$ level $\left(\mathrm{T}^{\prime}=6.4, \mathrm{~T}^{\prime}(5 \%)=28.9\right.$, $v=18$ ) and their weighted mean is $334 \pm 6 \mathrm{BP}$. If the $\mathrm{C}_{16: 0}$ and $\mathrm{C}_{18: 0}$ FAs for each piece 
are combined (as would usually be the case when reporting an age of a pottery vessel), the results are also statistically consistent $\left(\mathrm{T}^{\prime}=1.8, \mathrm{~T}^{\prime}(5 \%)=16.9, v=9\right)$ and give a weighted mean of $334 \pm 8$ BP. The CSRA weighted means are statistically indistinguishable from the those obtained on bulk measurements $\left(\left(\mathrm{T}^{\prime}=0.5, \mathrm{~T}^{\prime}(5 \%)=3.8, v=1\right.\right.$ and $\mathrm{T}^{\prime}=0.5, \mathrm{~T}^{\prime}(5 \%)$ $=3.8, \nu=1$ and $\mathrm{T}^{\prime}=0.3, \mathrm{~T}^{\prime}(5 \%)=3.8, \nu=1$ and $\mathrm{T}^{\prime}=0.5, \mathrm{~T}^{\prime}(5 \%)=3.8, \nu=1$ and, for the individual and combined measurements of FAs, respectively). Taken all together, individual bulk and CSRA ages determined for the bog butter specimen IB38 are statistically indistinguishable whether we use the individual $\left(\mathrm{T}^{\prime}=12, \mathrm{~T}^{\prime}(5 \%)=42.6, \nu=\right.$ 29 ) or combined $\left(\mathrm{T}^{\prime}=7.2, \mathrm{~T}^{\prime}(5 \%)=30.1, \nu=19\right)$ ages of the two FAs. The weighted mean was found to be $338 \pm 3 \mathrm{BP}$ in both cases.

These results demonstrate that the prepared bog butter specimens are homogeneous in age whether we use a bulk or a compound-specific approach. The results also confirm that no exogenous carbon is introduced during the pcGC protocol in any quantity that would significantly affect the CSRA determinations.

\section{CONCLUSION}

We have identified and selected two ideal bog butter specimens to produce radiocarbon standards. The specimens were cleaned from contaminants and homogenized. They have been proven to be homogenous in their lipid composition, stable carbon isotope ratios and radiocarbon ages and are, therefore, suitable for use as quality control standards.

These two new bog butter standards are ideally suited for use in the compound-specific radiocarbon analyses of FAs, particularly the $\mathrm{C}_{16: 0}$ and $\mathrm{C}_{18: 0}$ FAs, isolated from archaeological matrices such as pottery vessels, human/animal remains or other fat-based commodities, e.g. cosmetics. At the BRAMS facility, we now routinely use these processing-standards in batches of unknown age samples of fatty acids (currently alongside our pseudo-processing standards as described in the introduction).

We dated the two bog butter standards to $3777 \pm 4$ BP (IB33) and $338 \pm 3$ BP (IB38). These samples will be subjected to an intercomparison exercise with other laboratories equipped with or having access to compound-specific capabilities and AMS instruments in order to provide robust consensus values for these two new standards. Subject to the outcome of this exercise, the ultimate intention will be to make these two new standards available to the wider radiocarbon community under license and by permission of the National Museum of Ireland.

\section{ACKNOWLEDGMENTS}

We acknowledge the European Research Council for funding a Proof of Concept grant (LipDat, H2020 ERC-2018-PoC/812917) to RPE and financing EC's post-doctoral contract. We acknowledge C. Smith, Conservation Dept., National Museum of Ireland for facilitating access to the bog butter specimens and for supervising the entire sampling process. We thank the NERC (Ref. CC010) and NEIF (www.isotopesuk.org) for funding and maintenance of GC/MS and GC-C-IRMS instruments used in this work. All samples for ${ }^{14} \mathrm{C}$ dating were prepared and analyzed at the BRAMS facility and we acknowledge NERC, BBSRC, and the University of Bristol for capital funding for the facility. 


\section{REFERENCES}

Berstan R, Dudd SN, Copley MS, Morgan ED, Quye A, Evershed RP. 2004. Characterisation of "bog butter" using a combination of molecular and isotopic techniques. Analyst 129: 270-275.

Boaretto E, Bryant C, Carmi I, Cook G, Gulliksen S, Harkness D, Heinemeier J, McClure J, McGee E, Naysmith P, Possnert G, Scott M, van der Plicht H, van Strydonck M. 2002. Summary findings of the fourth international radiocarbon intercomparison (FIRI) (1998-2001). Journal of Quaternary Science 17:633-637.

Bryant C, Carmi I, Cook G, Gulliksen S, Harkness D, Heinemeier J, McGee E, Naysmith P, Possnert G, Scott M, van der Plicht $\mathrm{H}$, van Strydonck M. 2000. Sample requirements and design of an interlaboratory trial for radiocarbon laboratories, Nuclear Instruments and Methods in Physics Research Section B: Beam Interactions with Materials and Atoms 172:355-358.

Casanova E, Knowles TDJ, Williams C, Crump MP, Evershed RP. 2017. Use of a $700 \mathrm{MHz}$ NMR microcryoprobe for the identification and quantification of exogenous carbon in compounds purified by preparative capillary gas chromatography for radiocarbon determinations, Analytical Chemistry 89: 7090-7098.

Casanova E, Knowles TDJ, Williams C, Crump MP, Evershed RP. 2018. Practical considerations in high precision compound-specific radiocarbon dating: Eliminating the effects of solvent and sample cross-contamination on accuracy and precision, Analytical Chemistry 90:11025-11032.

Casanova E, Knowles TDJ, Bayliss A, Dunne J, Barański MZ, Denaire A, Lefranc P, di Lernia S, Roffet-Salque M, Smyth J, Barclay AJ, Gillard T, Claßen E, Coles BJ, Illet M, Jeunesse C, Krueger M, Marciniak A, Minnitt S, Rotunno R, van de Velde P, van Wijk I, Cotton J, Daykin A, Evershed RP. 2020a. Accurate compound-specific ${ }^{14} \mathrm{C}$ dating of archaeological pottery vessels. Nature 580: 506-510.

Casanova E, Arbogast R-M, Denaire A, Jeunesse C, Lefranc P, Evershed RP. 2020b. Spatial and temporal disparities in human subsistence in the Neolithic Rhineland gateway. Journal of Archaeological Science 122:105215.

Casanova E, Knowles TDJ, Ford C, Cramp LJE, Sharples N, Evershed RP. 2020c. Compoundspecific radiocarbon, stable carbon isotope and biomarker analysis of mixed marine/terrestrial lipids preserved in archaeological pottery vessels. Radiocarbon 62:1679-1697. doi: 10. 1017/RDC.2020.11.

Charters S, Evershed RP, Goad LJ, Leyden A, Blinkhorn PW, Denham V. 1993. Quantification and distribution of lipid in archaeological ceramics: implications for sampling potsherds for organic residue analysis and the classification of vessel use. Archaeometry 35: 211-223.

Copley MS, Berstan R, Dudd SN, Docherty G, Mukherjee AJ, Straker V, Payne S, Evershed RP. 2003. Direct chemical evidence for widespread dairying in prehistoric Britain. Proceedings of the National Academy of Sciences 100:1524-1529.

Correa-Ascencio M, Evershed RP. 2014. High throughput screening of organic residues in archaeological potsherds using direct acidified methanol extraction. Analytical Methods 6: 1330-1340.

Cronin T, Downey L, Synnott C, McSweeney P, Kelly EP, Cahill M, Ross RP, Stanton C. 2007. Composition of ancient Irish bog butter. International Dairy Journal 17:1011-1020.

Downey L, Synnott C, Kelly EP, Stanton C. 2006. Bog butter: dating profile and location. Archaeology Ireland 20:32-34.

Dunne J, Grillo KM, Casanova E, Whelton HL, Evershed RP. 2019. Pastoralist foodways recorded in organic residues from pottery vessels of the modern Samburu Kenya. Journal of Archaeological Methods and Theory 26: 619-642.

Earwood C. 1997. Bog butter: a two thousand year history. Journal of Irish Archaeology 8:25-42.

Evershed RP, Dudd SN, Copley MS, Berstan R, Stott AW, Mottram H, Buckley SA, Crossman Z. 2002. Chemistry of archaeological animal fats. Accounts of Chemical Research 35:660-668.

Fewlass H, Mitchell PJ, Casanova E, Cramp LJE. 2020. Chemical evidence of dairying by huntergatherers in highland Lesotho in the late first millennium AD. Nature Human Behaviour 4:791-799.

Mattiangeli V, Cooke NP, Ó’Maoldúin R, Sikora M, Mulhall I, Bradley DG, Teasdale MD. 2020. Genomic analysis of Irish bog butter. Journal of Archaeological Science: Reports 31, June.

Reimer PJ, Austin WEN, Bard E, Bayliss A, Blackwell PG, Ramsey CB, Butzin M, Cheng H, Edwards RL, Friedrich M, Grootes PM, Guilderson TP, Hajdas I, Heaton TJ, Hogg AG, Hughen KA, Kromer B, Manning SW, Muscheler R, Palmer JG, Pearson C, van der Plicht J, Reimer RW, Richards DA, Scott EM, Southon JR, Turney CSM, Wacker L, Adolphi F, Büntgen U, Capano M, Fahrni SM, Fogtmann-Schulz A, Friedrich R, Köhler P, Kudsk P, Miyake F, Olsen J, Reinig F, Sakamoto M, Sookdeo A, Talamo S. 2020. The IntCal20 Northern Hemisphere radiocarbon age calibration curve (0-55 cal kBP). Radiocarbon 62(4):725-757. doi: 10.1017/RDC. 2020.41

Rozanski K, Stichler W, Gonfiantini R, Scott EM, Beukens RP, Kromer B, van der Plicht J. 1992. 
The IAEA ${ }^{14} \mathrm{C}$ intercomparison exercise 1990 . Radiocarbon 34:506-519.

Scott EM, Boaretto E, Bryant C, Cook GT, Gulliksen $\mathrm{S}$, Harkness DD, Heinemeier J, McGee E, Naysmith P, Possnert G, van der Plicht H, van Strydonck M. 2004. Future needs and requirements for AMS ${ }^{14} \mathrm{C}$ standards and reference materials. Nuclear Instruments and Methods in Physics Research Section B: Beam Interactions with Materials and Atoms 223-224:382-387.

Smyth J, Berstan R, Casanova E, McCormick F, Mulhall I, Sikora M, Synnott C, Evershed RP. 2019. Four millennia of dairy surplus and deposition revealed through compound-specific stable isotope analysis and radiocarbon dating of Irish bog butters. Scientific Reports 9:4559.

Stojanovski D, Roffet-Salque M, Casanova E, Knowles T, Oosterbeek L, Evershed RP, Cruz A, Thissen L, Arzarello M. 2020a. Anta 1 de Val da Laje - The first direct view at diet dairying practice and socio-economic aspects of pottery use in the final Neolithic of central Portugal. Quaternary International 542:1-8.
Stojanovski D, Živaljević I, Dimitrijević V, Dunne J, Evershed RP, Balasse M, Dowle A, Hendy J, McGrath K, Fischer R, Speller C, Jovanović J, Casanova E, Knowles T, Balj L, Naumov G, Putica A, Starović A, Stefanović S. 2020b. Living off the land: terrestrial-based diet and dairying in the farming communities of the Neolithic Balkans. PLOS ONE 15(8):e0237608.

Synnott C, Downey L. 2004. Bog butter: its historical context and chemical composition. Archaeology Ireland 18:32-35.

Synnott C. 2010. A survey of the published reasons for burying butter in bogs. Ulster Journal of Archaeology 69:141-149.

Synnott C. 2014. Bog butter- What is it, where was it found and when and why was it put there? Butter in Ireland from the earliest times to the 21st century. Cork Butter Museum. 171-194.

Synnott C, Sikora M. 2018. New dates for old butter. Archaeology Ireland 32:26-29.

Ward GK, Wilson SR. 1978. Procedures for comparing and combining radiocarbon age determinations: a critique. Archaeometry 20:19-31. 